\title{
Research on the Performance of Coupling Coordination between IT Service and Manufacturing
}

\author{
Feng Liu \\ School of Economics \\ Hefei University of Technology \\ Hefei, China 230009
}

\author{
Qin Xu \\ School of Economics \\ Hefei University of Technology \\ Hefei, China 230009
}

\begin{abstract}
We analyze the way by which IT services and manufacturing industries affect each other theoretically. Introducing the capacity coupling model in physics, from the angle of industry system, we study the relation between IT service and manufacturing industries so as to build the theoretical model of industry coupling. Through the establishment of the corresponding index system, selecting the 24 manufacturing industry subdivisions and IT services as the samples, we specifically measure the degree of coupling between manufacturing industry subdivisions and IT services. And on this basis, further introducing system GMM, we verify the effect the degree of coupling between manufacturing industry subdivisions and IT services have on the performance of manufacturing industries. The result shows that the degree of coupling between manufacturing industry and IT services varies according to the diversity of manufacturing industries, but they have sharp growth over time. The coupling coordination degree between manufacturing industries and IT services has significant promotion on the performance of manufacturing industries.
\end{abstract}

Keywords-IT service; manufacturing; entropy right method; coupling coordination degree; system GMM

\section{INTRODUCTION}

As mentioned in "Made in China 2025", manufacturing occupies the national strategic position in economic development of China which has been becoming a strong country in manufacturing because of size and cost advantages. However because the technological competitiveness of Chinese manufacturing is still less than advanced countries', with disappearance of the demographic dividend and the rise of cost, there is a big change in Chinese manufacturing. Therefore in a new technology and industry revolution, Chinese manufacturing must seize the opportunity to promote integration of IT and industrialization. The action-plan of "Internet Plus" has been point out in Report on The Work of The Government from Premier of the State Council Li Keqiang. "Internet plus traditional industries" is upgrade edition of integration of IT and industrialization, and will change traditional industries mode through IT thinking. As a result, there will be a far-reaching industry revolution because of integration of IT service and

Fund project: special fund project for Fundamental Research Operating Expenses of Central Universities: Analysis on "doublestranded structures" of intelligent manufacturing industrial enterprises and Study on Key Technology Selection(J2014HGXJ0156).

CLC: F424.3 Document code: A manufacturing. As showed in statistical data, in 2014 the proportion of industries using IT service in all industries is up to $83 \%$, while the proportion in manufacturing is up to $89.5 \%$, which show that integration of IT and industrialization has been developing powerfully. To advance integration of IT and industrialization, firstly promote coupling coordination between IT service and manufacturing, promote development of respective industry system, finally across industry boundaries and come into being industrial integration in which depended on huge development size and dominant position manufacturing can drive IT development [1]. Substantially, integration of IT and industrialization is just coupling coordination between IT service and manufacturing based on rapid development of IT. The integration degree between IT and manufacturing is mostly measured with the proportion of IT output value in total output value of every manufacturing by researchers [1] [2]. Since this method ignores complex industry association between IT industry and manufacturing and lacks of researching on internal conduction mechanism deeply, it may lead to errors. Based on above, research on coupling coordination between IT service and manufacturing, and economic benefits of the coupling coordination in manufacturing has been made in this paper, through calculating coupling coordination degree between IT service and manufacturing and studying performance for manufacturing, can give good guiding on promoting IT in manufacturing.

Alfonso.G (1998) studied the data from 1984 to 1992 and found that there are significant industrial integration of computer, communications and other electronic industry which improved themselves performances [3]. Chinese scholar Yu Rengang (1997) first studied industrial integration in China, and put forward that in view of increasing demand of service it was good to form integration of technology, industry and trade, and promote industry penetration of tertiary industry into the first and second industry, which gave great help for understanding industry structure and layout through industrial integration [4]. Since 21st Century, because of increasing industry development, close connection among industries and frequent crossindustry cooperation, industry theory has been promoted. Zhang Mingzhi (2014) believed that industrial integration is not simple diffusion of advanced technology into traditional industry, but also technology permeation into 
industrialization especially by high technology such as information technology.

Industrial coupling is the development of industrial integration theory. Yang Hong (2009) argued that industrial coupling is essentially a process of self organization which is decided by the relationship between two industries. If it is complementary relationship, they can be coupled directly [6]. Xiong Yongqing (2010) measured the logical relationship in time and space between strategic emerging industries and tradition industries, analyzed the coupling relationship of them in empirical research [7]. Tao Changqi (2015) researched on industrial coupling relationship between IT industries and manufacturing industry based on industry integration background, concluded that highly coupling between IT industry and manufacturing industry could promote optimization and upgrading of industrial structure [8]. However relevant literatures above mostly ignored the complexity and relevance of coupling system between IT service and manufacturing which were not studied as a depth and a three-dimensional system. Therefore it is very urgency to find related variables which improve manufacturing performance and put forward some corresponding policy suggestions, through studying the coupling relationship between IT service and manufacturing.

\section{ASSESSMENT OF COUPLING COORDINATION DEGREE BETWEEN IT SERVICE AND MANUFACTURING IN CHINA}

IT industry wasn't chose as a study object which includes IT manufacturing and IT service, hereinto IT manufacturing is a branch of manufacturing, as well as a branch of IT industry, is easy to cause endogenous problem for researching manufacturing performance. Therefore, IT service was chose for studying coupling with manufacturing in this paper.

\section{A. Coupling Function}

Assume that the system order parameter of IT service is $\mathrm{U}$, the $\mathrm{jth}$ index of the ith order parameter is ${ }^{X_{i j}}$, the upper limit of order parameter is $a_{i j}$, the lower limit of order parameter is $b_{i j}$. Hereinto $\mathrm{i}=1,2,3 \ldots, \mathrm{n} \mathrm{j}=1,2,3 \ldots, \mathrm{m}, \mathrm{n}$ is the index number of subsystem in IT service, $m$ is the parameter number of the ith index; manufacturing comprehensive order parameter is represented with $\mathrm{W}$, the jth index of the ith order parameter is ${ }^{y_{i j}}$, the upper limit of order parameter is $p_{i j}$, the lower limit of order parameter is $q_{i j}$. Hereinto $\mathrm{i}=1,2,3 \ldots \mathrm{n}, \mathrm{j}=1,2,3 \ldots, \mathrm{m}$ ', $\mathrm{n}$ ' is index number of subsystem in IT service, $m$ ' is parameter number of the ith index.

Efficacy functions of IT service and manufacturing as follows.

$$
U_{i j}=\left(x_{i j}-b_{i j}\right) /\left(a_{i j}-b_{i j}\right)\left(U_{i j} \text { has a positive effect }\right)
$$

$$
W_{i j}=\left(y_{i j}-q_{i j}\right) /\left(p_{i j}-q_{i j}\right)\left(W_{i j} \text { has a positive effect }\right)
$$

Assume that $\lambda_{i}$ represents the weight of the ith index in IT service subsystem, $\lambda_{i j}$ represents the weight of the jth parameter in the ith index. Then the comprehensive contribution value of IT service is $u_{i}$, the contribution value of IT service in index level is $u_{i j}$, Hereinto, $\mathrm{i}=1,2,3 \ldots, \mathrm{n}$ $\mathrm{j}=1,2,3 \ldots, \mathrm{m} ; \lambda_{i}$ represents the weight of the ith index in IT service subsystem, $\lambda_{i j}$ represents the weight of the jth parameter in the ith order parameter.

Contribution model in index level and comprehensive contribution model in industry level of IT service.

$$
\begin{aligned}
& U_{i}=\sum_{j=1}^{m} \lambda_{i j} * u_{i j} \\
& U=\sum_{i=1}^{n} \lambda_{i} * u_{i}
\end{aligned}
$$

(Hereinto $\sum_{j=1}^{m} \lambda_{i j}=1 \quad$ )

In which, $\sigma_{i}$ represents the weight of the ith index in manufacturing subsystem, $\sigma_{i j}$ represents the weight of the $\mathrm{jth}$ parameter in the ith index. Then the comprehensive contribution value of manufacturing is $W_{i}$, the contribution value of manufacturing in index level is ${ }^{W_{j j}}$.Hereinto, $\mathrm{i}=1,2,3 \ldots, \mathrm{n} \mathrm{j}=1,2,3 \ldots, \mathrm{m} ; \sigma_{i}$ represents the weight of the ith index in manufacturing subsystem, $\sigma_{i j}$ represents the weight of the jth parameter in the ith index.

Contribution model in index level and comprehensive contribution model in industry level of manufacturing.

$$
\begin{aligned}
& W_{i}=\sum_{j=1}^{m} \sigma_{i j} * u_{i j} \\
& W=\sum_{i=1}^{n} \sigma_{i} * u_{i} \\
& \text { (Hereinto } \sum_{j=1}^{m^{\prime}} \sigma_{i j}=1
\end{aligned}
$$

Multisystem coupling model is obtained by reference of capacity coupling model in physics [9].

$$
C_{n}=n\left\{\left(u_{1} \cdot u_{2} \ldots u_{m}\right) /\left(\prod u_{i}+u_{j}\right)\right\}^{\frac{1}{n}}
$$


Hereinto, $u_{i}$ represents comprehensive development of subsystem, in view of research on coupling of IT service and manufacturing in this paper, the model is simplified as follows.

$$
C=2 \sqrt{u_{1} \cdot u_{2}} /\left(u_{1}+u_{2}\right)
$$

Hereinto, the value range of $\mathrm{C}$ is $(0,1)$. When $\mathrm{C}=0$, shows that the coupling degree of IT service and manufacturing is minimum, and still at the stage of germination, meaning noncoupling; while $0<\mathrm{C} \leq 0.3$, the coupling degree is smaller, and just at the stage of formation, meaning lower coupling; while $0.3<\mathrm{C} \leq 0.7$, the coupling degree is larger, and just at the stage of development, meaning intermediate coupling; while $0.7<\mathrm{C} \leq 1$, the coupling degree is greater, and just at the stage of ripeness, meaning high-level coupling.

\section{B. Assessment Model of Coupling Coordination between IT Service and Manufacturing}

Coupling degree, as a important index representing coupling between IT service and manufacturing, has good help to assess the strength of mutual effect between IT service and manufacturing. However, since the mutual effect between them is stagger, and does not keep balance, both the comprehensive development degree(U,W)of IT service and manufacturing are low. But when they are similar, the coupling degree $\mathrm{C}$ is higher, meaning pseudo coupling with a model as follows referring to relevant scholars' research.

$$
D=(C \cdot T)^{\frac{1}{2}}
$$

In which, D represents coupling coordination degree, $T=\alpha u+\beta W, \mathrm{~T}$ represents comprehensive assessment index of IT service and manufacturing, $\alpha$ and $\beta$ are undetermined coefficients which represents contribution coefficient of IT service and manufacturing [9]. Here $\alpha$ is 0.6 , and $\beta$ is 0.4 .

An index system of IT service and manufacturing subindustries is built in four aspects as follows. "Table I"

The index weight is determined by combining with subjective rating and objective weighting in this paper. Hereinto, the first grade weights are obtained by Delphi Method, combined with expert rating and relevant literatures, in which the size, structure, potential weight respectively is $0.3 、 0.25,0.25,0.2$. And the second grade weights are determined by Entropy Weighting Method with steps as follows.

$$
\begin{aligned}
& \quad \text { Standardization for } \\
& y_{i j}=\left(x_{i j}-b_{i j}\right) /\left(a_{i j}-b_{i j}\right)
\end{aligned}
$$

(3) Calculation for information entropy of indexes: $e_{j}=-k \sum_{i=1}^{m} S_{i j} \ln S_{i j}\left(k=\frac{1}{\ln m}\right)$

(4) Calculation for information entropy redundancy: $d_{j}=1-e_{j}$

(5) Calculation for each index weight respectively $\omega_{j}=d_{j} / \sum_{j=1}^{n} d_{j} \omega_{j \leq 1)}$

TABLE I. COUPLING INDEX SYSTEM OF IT SERVICE AND MANUFACTURING

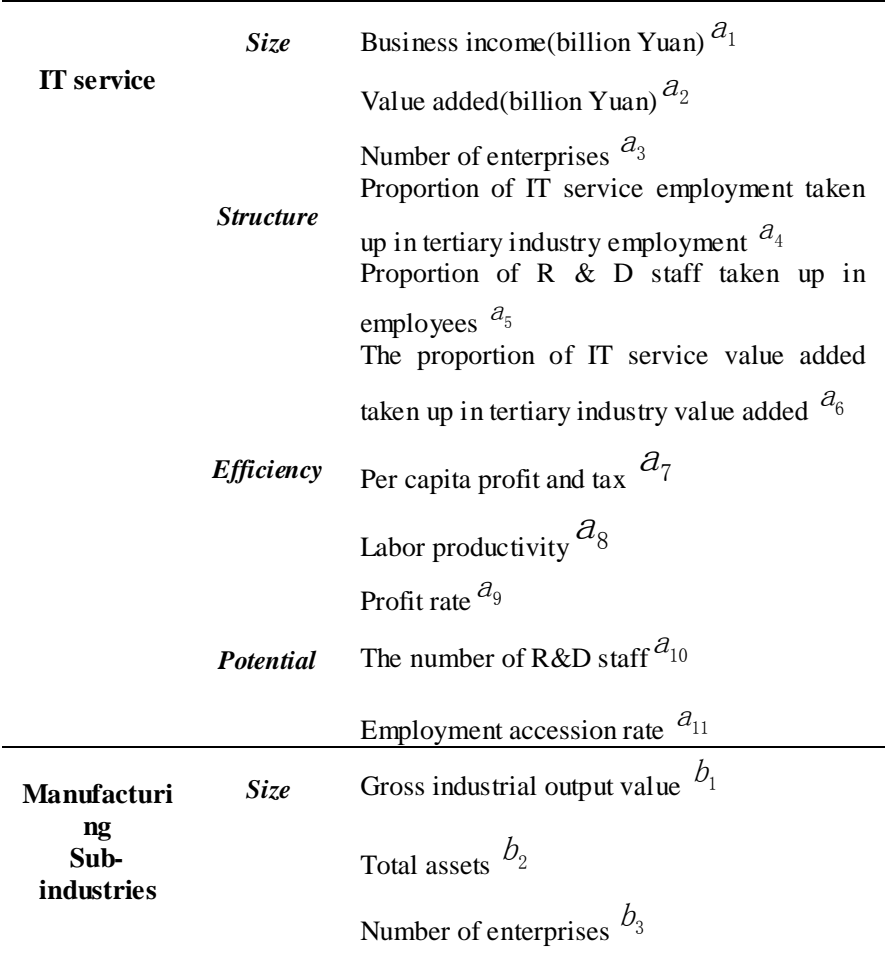

Proportion of sub-industries employmen taken up in manufacturing employment $b_{4}$ Proportion of the enterprises taken up in total enterprises of manufacturing $b_{5}$ Sub-industries value added / manufacturing value added $b_{6}$

Efficiency Per capita profit and tax $b_{7}$ Per capita sales $b_{8}$ Profit ratio of sales $b_{9}$

Potential Turnover of total capital $b_{10}$ Return of equity $b_{11}$

accession rate of employment=current employment number /prior period employment number-1, labor productivity=production value/e mployment number, per capita profit and tax =total tax/employment number, turnover of total capital= business net revenue/average total assets, return of equity=net profit/average assets 


\section{Sample Selection and Data Source}

Excluding plastics industry, automobile manufacturing, railway, marine, aerospace and other transportation equipment manufacturing because of different statistical caliber and lack of samples, and excluding communications equipment, computers and other electronic equipment manufacturing due to endogenous problems in the enterprises manufacturing IT products which mostly provide IT service, according to national industry classification standard, finally 24 sub-industries of manufacturing have been selected with industry data from 2003 to 2013. And the data of IT service comes from the data of information transmission industry, software, and IT service industry during 2003 to 2013. Some data involving gross output value and assets should be taken price conversion based on the price of 2003. Data come from "Statistical Yearbook of China", "Statistical Yearbook of tertiary industry", "Yearbook of China Information", and China statistical data application support system, website data of Ministry of Chinese industrialization and informationization, which is handled with Excel and MATLAB software. "Table II"

As shown in time dimension in "Table III", the coupling coordination degree of manufacturing sub-industries and IT service exhibits fluctuating uprising tendency in time dimension; while as shown in industry dimension, the coupling coordination degrees of tobacco products industry with industry code of 16 and petroleum processing, coking and nuclear fuel processing with industry code of 29 with IT service are small, and other sub-industries exhibit good coupling coordination with IT service with time.
TABLE II.

INDUSTRY CLASSIFICATION OF SAMPLE

\begin{tabular}{ll}
\hline $\begin{array}{c}\text { Industry } \\
\text { Code }\end{array}$ & \multicolumn{1}{c}{ Name } \\
\hline 13 & Agricultural and sideline food processing industry \\
14 & Food manufacturing industry \\
15 & Beverage manufacturing industry \\
16 & Tobacco products industry \\
17 & Textile industry \\
18 & Textile and garment, shoes, cap Manufacturing industry \\
19 & Leather, fur, feather (down) and its products industry \\
20 & Wood processing and wood, bamboo, rattan, palm, grass \\
21 & products industry \\
22 & Furniture manufacturing industry \\
23 & Paper and paper products industry \\
24 & Printing and recording media reproduction \\
25 & Stationery and sporting goods manufacturing industry \\
26 & Petroleum processing, coking and nuclear fuel processing \\
27 & Chemical raw materials and chemical products \\
28 & manufacturing mand \\
30 & Pharmaceutical manufacturing industry \\
31 & Chemical fiber manufacturing \\
32 & Non metallic mineral products industry \\
33 & Ferrous metal smelting and rolling processing industry \\
34 & Non-ferrous metal smelting and rolling processing \\
35 & industry \\
38 & Metal products industry \\
42 & General equipment manufacturing industry \\
\hline & Special equipment manufacturing industry \\
\hline & Electrical machinery and equipment manufacturing \\
industry & Comprehensive utilization of waste resources \\
\hline
\end{tabular}

TABLE III. COUPLING COORDINATION DEgREe of MANUFACTURING AND IT SERVICE(D)

\begin{tabular}{|c|c|c|c|c|c|c|c|c|c|c|c|}
\hline Industry Code & 2003 & 2004 & 2005 & 2006 & 2007 & 2008 & 2009 & 2010 & 2011 & 2012 & 2013 \\
\hline 13 & 0.133 & 0.297 & 0.426 & 0.524 & 0.557 & 0.612 & 0.709 & 0.788 & 0.857 & 0.915 & 0.923 \\
\hline 14 & 0.196 & 0.305 & 0.436 & 0.435 & 0.560 & 0.601 & 0.718 & 0.790 & 0.857 & 0.911 & 0.935 \\
\hline 15 & 0.243 & 0.309 & 0.444 & 0.459 & 0.571 & 0.600 & 0.711 & 0.778 & 0.859 & 0.905 & 0.919 \\
\hline 16 & 0.368 & 0.456 & 0.549 & 0.555 & 0.606 & 0.543 & 0.609 & 0.673 & 0.743 & 0.766 & 0.770 \\
\hline 17 & 0.292 & 0.402 & 0.513 & 0.638 & 0.605 & 0.613 & 0.695 & 0.795 & 0.841 & 0.860 & 0.906 \\
\hline 18 & 0.248 & 0.339 & 0.447 & 0.547 & 0.552 & 0.592 & 0.677 & 0.757 & 0.807 & 0.917 & 0.898 \\
\hline 19 & 0.253 & 0.347 & 0.460 & 0.468 & 0.567 & 0.586 & 0.682 & 0.774 & 0.827 & 0.911 & 0.900 \\
\hline 20 & 0.099 & 0.297 & 0.422 & 0.456 & 0.560 & 0.616 & 0.713 & 0.785 & 0.853 & 0.915 & 0.932 \\
\hline 21 & 0.183 & 0.338 & 0.444 & 0.447 & 0.560 & 0.608 & 0.705 & 0.791 & 0.847 & 0.901 & 0.927 \\
\hline 22 & 0.309 & 0.421 & 0.531 & 0.558 & 0.628 & 0.648 & 0.690 & 0.810 & 0.847 & 0.868 & 0.872 \\
\hline 23 & 0.278 & 0.378 & 0.462 & 0.588 & 0.557 & 0.592 & 0.668 & 0.743 & 0.790 & 0.885 & 0.909 \\
\hline 24 & 0.219 & 0.298 & 0.381 & 0.369 & 0.449 & 0.465 & 0.533 & 0.603 & 0.626 & 0.921 & 0.869 \\
\hline 25 & 0.285 & 0.440 & 0.458 & 0.429 & 0.545 & 0.686 & 0.739 & 0.836 & 0.786 & 0.760 & 0.815 \\
\hline 26 & 0.222 & 0.371 & 0.468 & 0.541 & 0.584 & 0.614 & 0.691 & 0.794 & 0.869 & 0.901 & 0.923 \\
\hline 27 & 0.232 & 0.308 & 0.430 & 0.441 & 0.549 & 0.592 & 0.702 & 0.776 & 0.852 & 0.905 & 0.931 \\
\hline 28 & 0.311 & 0.395 & 0.487 & 0.467 & 0.619 & 0.532 & 0.672 & 0.831 & 0.887 & 0.823 & 0.841 \\
\hline 30 & 0.160 & 0.306 & 0.388 & 0.474 & 0.545 & 0.605 & 0.707 & 0.791 & 0.870 & 0.911 & 0.932 \\
\hline 31 & 0.295 & 0.447 & 0.536 & 0.519 & 0.641 & 0.660 & 0.676 & 0.779 & 0.843 & 0.853 & 0.863 \\
\hline 32 & 0.232 & 0.378 & 0.488 & 0.672 & 0.637 & 0.624 & 0.686 & 0.812 & 0.861 & 0.881 & 0.860 \\
\hline 33 & 0.204 & 0.327 & 0.436 & 0.584 & 0.552 & 0.607 & 0.684 & 0.775 & 0.831 & 0.916 & 0.917 \\
\hline 34 & 0.217 & 0.364 & 0.471 & 0.480 & 0.591 & 0.648 & 0.729 & 0.819 & 0.869 & 0.886 & 0.916 \\
\hline 35 & 0.190 & 0.332 & 0.430 & 0.499 & 0.573 & 0.624 & 0.717 & 0.803 & 0.865 & 0.905 & 0.925 \\
\hline 38 & 0.229 & 0.351 & 0.456 & 0.473 & 0.579 & 0.632 & 0.721 & 0.810 & 0.858 & 0.890 & 0.922 \\
\hline 42 & 0.075 & 0.346 & 0.442 & 0.471 & 0.554 & 0.625 & 0.722 & 0.816 & 0.856 & 0.888 & 0.917 \\
\hline
\end{tabular}




\section{EFFECT MODEL AND EMPIRICAL ANALYSIS OF COUPLING COORDINATION DEGREE ON MANUFACTURING PERFORMANCE}

\section{A. Model Design}

Although it is clear about relationship between IT service and manufacturing, there is a divergence about the effect of the relationship on manufacturing performance. Some scholars believe that the integration of IT service and manufacturing has been promoting manufacturing performance with a multiplier effect [1]; while some other scholars think that although the integration of IT service and manufacturing has promoted manufacturing, which has not obvious effect on manufacturing performance, even has a block for manufacturing performance [2].

In order to clarify the effect of the relationship between IT service and manufacturing on manufacturing performance, the effect of coupling coordination degree between IT service and manufacturing on manufacturing performance is explained as follows.

Building model as follows:

$$
T A C=\alpha+\beta D+\mu
$$

In which, the total assets contribution TAC is used to measure performance of manufacturing sub-industry $\mathrm{i}$; $\mathrm{D}$ is the coupling coordination degree of IT service and manufacturing calculated above during 2003 to 2013; $\mu$ represents random error.

Since the performance of prior period has a effect on the current period combined with actual situation, the one-period delay of explanatory variables is added in the model.

$$
T A C_{i, t}=\alpha_{i, t}+\beta_{1} D_{i, t}+\beta_{2} T A C_{i, t-1}+\mu_{i, t}
$$

(i represents industry section; $t$ represents time section.)

Actually there are other factors effecting on manufacturing performance which are added in the model.

According to relevant literatures, the larger enterprise size is and the more concentration of market is, the stronger the ability of enterprise accessing to resource from the market, the more effect on performance promoting. Enterprise size of Industry (i) =Industry (i) gross output value/total enterprises number of Industry (i).

Market openness (Open) has some effect on industry performance. FDI can represents industry openness, Industry (i) openness =FDI/ Paid- in capital in Industry (i) $* 100 \%$.
Enterprise labor productivity (Lp) can promote industry performance. Labor productivity of Industry (i) = industry value added / industry employment number, the data in empirical analysis is taken the logarithm.

Based on above analysis and literatures, the following hypothesis is given as follows.

$H_{1}$ : The coupling coordination degree of IT service and manufacturing can dramatically promote manufacturing performance.

$H_{2}$ : Good performance in prior period can promote current performance in manufacturing.

$H_{3}$ : The larger enterprise size of manufacturing subindustry, the more market concentration, it is conducive to the realization of economies of scale and promote industry performance.

$H_{4}$ : The stronger manufacturing industry openness, is conducive to introduce foreign capital and promote manufacturing performance.

$H_{5}$ : The higher the labor productivity of manufacturing is, the more conducive to improve industry performance.

According to the above analysis, control variable is added in the model as follows.

TAC $_{i, t}=\alpha_{i, t}+\beta_{1} D_{i, t}+\beta_{2}$ TAC $_{i, t-1}+\beta_{3} \log \left(\right.$ Size $\left._{i, t}\right)+\beta_{4}$ Open $_{i, t}+\beta_{5} \log \left(L P_{i, t}\right)+\mu_{i, t}$

The industries sample is still 24 sub-industries as mentioned above from 2003 to 2013. The data involving output value have been taken price conversion using industry gross output value exponent based on the data of 2003.

Since an explanatory variables delay is added in the model which is a typical dynamic model, the endogenous problems come which can be solved by selection of instrumental variable. It is difficult to select instrumental variable, however CMM system can deal with that includes a lag phase variable as a first difference instrumental variable which is as an instrumental variable of level variable, and can make results valid [10].

\section{B. Empirical Analysis}

Descriptive statistics and correlation test of sample variables "Table IV"

TABLE IV. DESCRIPTIVE AND CORRELATION STATISTICS

\begin{tabular}{cllllllll}
\hline Variable & Sample number & \multicolumn{1}{c}{ Average value } & Variance & TAC & D & $\log (\operatorname{Size})$ & Open & Log(LP) \\
\hline TAC $\%$ & 264 & 16.44697 & 12.30826 & 1 & & & & \\
D & 264 & 0.6189312 & 0.2166822 & 0.2617 & 1 & & & \\
$\log ($ Size $)$ & 262 & 0.1670912 & 0.0786712 & 0.3968 & -0.1851 & 1 & & \\
Open & 264 & 2.741047 & 0.3437021 & 0.4788 & 0.1263 & -0.5386 & 1 & \\
$\log ($ Lp $)$ & 264 & 5.108741 & 0.4571651 & 0.6333 & 0.4638 & -0.1003 & 0.2986 & 1 \\
\hline
\end{tabular}


There is a dramatic and positive correlation between gross assets contribution and coupling coordination degree (D) of IT service and manufacturing, which is also consistent with the Hypothesis 1 .

The stationary test is taken for the variables in the model to avoid spurious regression which are passed the stationary test and meet the stability requirements (omitting because of length confined in this paper). "Table V"

TABLE V. REGRESSION RESULTS OF SYS-GMM DYNAMIC PANEL DATA MODEL

\begin{tabular}{cll}
\hline Variable & \multicolumn{1}{c}{ Model } & \multicolumn{1}{c}{ Model } \\
\hline $\mathbf{D}$ & $\begin{array}{l}7.58655^{* *} \\
(2.440)\end{array}$ & $\begin{array}{l}18.02908^{* *} \\
(2.538)\end{array}$ \\
$T A C_{i, t-1}$ & $1.01595^{* * *}$ & $0.88842^{* * *}$ \\
& $(27.519)$ & $(7.303)$ \\
Log(size) & & 2.85633 \\
& & $(0.830)$ \\
Open & & 0.49490 \\
& & $(0.147)$ \\
Log(lp) & & $1.05767 * *$ \\
Arellano-Bond & 0.242 & 0.0021 \\
test for AR(1) & & 0.451 \\
Arellano-Bond & 0.721 & 0.952 \\
test for AR(2) & & \\
Hansen test & 0.967 & \\
\hline & $* * *, * *$ represent respetively $1 \%, 5 \%$ and $10 \%$ test.
\end{tabular}

Although the original hypothesis AR (1), AR (2) respectively are inexistence of first-order serial correlation and second-order serial correlation, the SYS-GMM requires inexistence of second-order serial correlation, and allows existence of first-order serial correlation. All values of $\mathrm{P}$ in AR (2) test are more than 0.1 , which is mean inexistence of second-order self-correlation. Because Robust Estimation is used in this paper, Hansen values are reported. The Hansen test $P$ values of the two models in Table 5 are more than 0.1 , which is mean that the selection of instrumental variables are effective.

In order to compare conveniently, the results of two columns respectively are the results before and after adding with control variables. Furthermore combined with the hypothesis of this paper, we can draw the following conclusions.

- In view of explanatory variables, the coupling coordination degree of IT service and manufacturing D is significantly positive and greater values, which show that there is a dramatic positive correlation between total assets contribution of manufacturing sub-industry and coupling coordination degree of IT service and manufacturing D. When D increases, manufacturing performance is promoted dramatically, which is verified Hypothesis H1. Therefore in order to improve manufacturing performance, promote integration of IT service and manufacturing and increase $\mathrm{D}$.

- The prior period performance of manufacturing industry has a significant positive effect on the current period, which is also consistent with the current situation of economic development, and verified Hypothesis $\mathrm{H} 2$.

- The variable of enterprise size is positive, and not significant, which shows that there is an inconspicuous effect of enterprise size on manufacturing performance in the sub-industry that isn't formation of scale economies, maybe because the enterprise size can promote the output, but has a inconspicuous effect on profit rising. This is not entirely consistent with Hypothesis H3 of this paper, which shows that the size of manufacturing enterprises in our country at the present stage has a certain effect on manufacturing performance, but is not obvious.

- The variable coefficient of market openness is positive, which shows that the opening market environment in manufacturing plays a role to improve manufacturing performance which is not remarkable and doesn't pass the significant test. Thereby on the one hand it is indeed that FDI plays a certain role to improve manufacturing performance; on the other hand, FDI promotes economic development through technology spillover which is lag and slow and can make a crowding out effect on domestic investment, is inconspicuous contribution to economic growth [11].

- Labor productivity is positive, and passes 5\% significance testing, which show that promotion of productivity can improve industry performance and verified Hypothesis H5.

\section{CONCLUSION AND POLICY SUGGESTION}

In the process of industrialization, coupling of IT service and manufacturing is a important way to adjust manufacturing industry structure of China and realize manufacturing transformation and upgrading. The coupling coordination degrees of 24 manufacturing sub-industries and IT service have been obtained through capacity coupling model in this paper, indicate that all coupling coordination degrees display fluctuation growths, furthermore conclude that the coupling coordination degrees of tobacco industry and petroleum processing, coking and nuclear fuel processing is relatively low and need to increase communication and cooperation with IT service. Introducing the SYS- GMM model, taking total assets contribution as a explained variable and the coupling coordination degree as a explanatory variable, adding enterprise size, market openness and labor productivity as control variables, verify that coupling coordination degree plays dramatic role to improve manufacturing performance, while other control variables also have certain effects on manufacturing performance which are not repeated here. Therefore actively promoting coupling development of IT service and manufacturing, is an important way to improve manufacturing performance, and is an urgent problem in the process of industrialization of China, as well as a new trend of industry development.

With cloud computing, big data, mobile Internet and other emerging IT concepts proposed, IT service has been changing from traditional IT to emerging IT, expanding business by 
combining with emerging technologies with development of their own advantages. Manufacturing should seize the opportunity of emerging technologies, and build a platform of "IT service plus manufacturing", so as to make an industrial synergy effect.

\section{REFERENCES}

[1] $\mathrm{Xu}$ Yingzhi, Sun Jian, Integration of Information Industry and Manufacturing Industry-Research on Performance Analysis [J], Chinese Industrial Economy, 2009, (07): 55-56.

[2] Wang Fang, Pan Maomao, Industry Integration, Improvement of Performance and Growth of Manufacturing Industry-Demonstration on the Basis of Panel Data During 1998 to 2011 [J], Studies in Science of Science, 2015, (04): 530-538.

[3] Alfonso.G,Salvatore.T, Does technological convergence imply convergence in market ?[J]. The Electronics Industry. research policy.1998, 27(05): 45-463.

[4] Yu Rengang, Three Industries Classification and Industrial Convergence Trend [J], World Economics and Politics, 1997, (01): 113119.

[5] Zhang Mingzhi, Research on Deep Integration of Industry in Construction of Modern Industrial System [J], Academic Exchanges, 2014, (03): 42-43.

[6] Yang Hong, Pu Yongjian. New Path of Sustainable Development of Undeveloped Area-Research on Ecological Agriculture, Ecological Tourism Coupling Industry [J], Management World, 2009, (04): 169170.

[7] Xiong Yongqing, Li Shicai. Discussion on Process and Mechanism of Action of Coupling Development of Strategic Emerging Industry and Traditional Industry [J], Science of Science and Management of Science and Technology, 2010, (11): 84-87.

[8] Tao Changqi, Zhou Xuan. Analysis on Optimization and Upgrading Effect of Industrial Structure under Industry Integration -Research on Real Evidence of Coupling of Information Industry and Manufacturing Industry [J], Industrial Economics Research, 2015, (03): 21-31.

[9] Du Chuanzhong, Wang Xin, Liu Zhongjing, Can Coupling and Collaboration of Manufacturing Industry and Productive Service Industry Improve Competitiveness of Economic Circle? -Comparison of Two Major Economic Circles Between Beijing-Tianjin-Hebei Region and Yangtze River Delta [J], Industrial Economics Research, 2013, (06): 19-28.

[10] Zhan Hua, Yu Jinping. Demonstration Examine of Influential Effect of Trade Openness on Environmental Pollution in Our Country-Analysis on System GMM of Inter-provincial Dynamic Panel Data in Our Country [J], Modern Economic Science, 2015, (01): 39-46.

[11] Yu Jinping, Xu Xiaoyu, Research on Economic Growth Pattern in Yangtze River Delta and Foreign Capital Utilization Effect [J], Journal of International Trade, 2011, (01): 72-81. 